\title{
On Implant-Registries
}

\author{
Peter A Ehrl* \\ Berlin, Germany
}

*Corresponding author: Peter A Ehrl, Berlin, Germany; E-mail: peter@ehrl.se

Received: 19 Jul, 2019 | Accepted: 12 Jul, 2019 | Published: 03 Aug, 2019

Citation: Ehrl PA (2019) On Implant-Registries. J Epidemiol Public Health Rev 4(2): dx.doi.org/10.16966/2471-8211.172

Copyright: (c) 2019 Ehrl PA. This is an open-access article distributed under the terms of the Creative Commons Attribution License, which permits unrestricted use, distribution, and reproduction in any medium, provided the original author and source are credited.

\begin{abstract}
An implant register can consist of a product and or patient registry. A Clinical Quality Registry (CQR) with treatment data also is conceivable. The quality of the register is determined by the quality of the data collection. Due to the complexity of the questions, the quality of possible evaluations and to avoid conflicts of interest, it is recommended to see these fields separately and to leave the evaluation to scientific studies. Conflicts of interest are indicated. The existence of a register has little benefit for the patient. In addition to the equally important approval procedures, problem management based on a register is crucial for patients. The detection of discrete abnormalities with the help of algorithms (artificial intelligence) can be seen as a project for the future. Besides the decisive parameters for the success of implants such as reliable approval procedures, good education and training of users and a quality-oriented working environment, the implant register represents an additional benefit. Due to the extremely complex nature of the problem, the question of resources has to be asked in relation to the different significance of the various implant applications.
\end{abstract}

Keywords: Human implants; Implant-registry; Implant-product-registry; Implant-patient-registry

\section{Introduction}

Implant registries existed since the 1980s [1]. First of all, the primary reason was to obtain information about the success of implants. Only by problems their meaning became more conscious. Best known is the scandal about breast implants [2-4]. Worldwide there should be about 7,000 implant types from about 900 manufacturers on the market $[5,6]$. With the increasing number of implantable medical devices, the number of problems also increases. As a result, there is an increasing need for security from the public and hence an increase in the activities of regulatory institutions. On the one hand there are increasing efforts by institutions involved in the approval and registration of implants (e.g. FDA, EU, CFDA, CDSCO, AFSSAPS) and on the other hand political efforts to establish implant registers. This is comprehensible clearly. However, this is only part of the problem.

\section{What is an Implant Register?}

An implant registry is to record implants and their parameters. This is particularly important for those involved, i.e. patients and doctors, but also for manufacturers, inventors, scientists and students. The basic ideas for such implant registers date back to the time of looseleaf compendia and must be reconsidered today. Previous registers are often not accessible and or understandable for patients.

Since it is about patients, an implant register must be thought from the perspective of the patient. This means that positive and negative aspects must be objectively discernible. This requires the combination of technical and biological knowledge about implants with individual patients. Here, in addition to the medical profession, the state also increasingly sees itself in its duty of care. One development can be observed, for example, where registers established by medical associations are transferred to state institutions.

There are two fields of implant registers.

\section{Implant product registry}

The registry related to the implant-we call it the "Implant Product Register"-is the basis for all further registrations. This raises the question of which properties of an implant should be recorded. In addition to the basic facts, further information can be considered, which can be of optional importance for users and patients. Explanations or links to explanations are important for patients as laypersons. Figure 1 shows possible recording data. As different as the implants are in different regions of the body, it is important to record them as systematically as possible in order to be able to compare them (Table 1).

As will be explained below, the implant product registry is also the space where all further data from implant patient registries and studies can be merged. Data could be provided in different scales, like in the implant-register with the brief profile with 9 items (preferably for laypersons) and full profile in 27 items.

Special questions: Special problems arise, for example, in the areas described below.

Customized implants: Since the 1950s, it has been common practice to radiologically test individually fabricated metal implants in two planes before inserting them. Although this no longer corresponds to today's need for security, it shows the way: a 


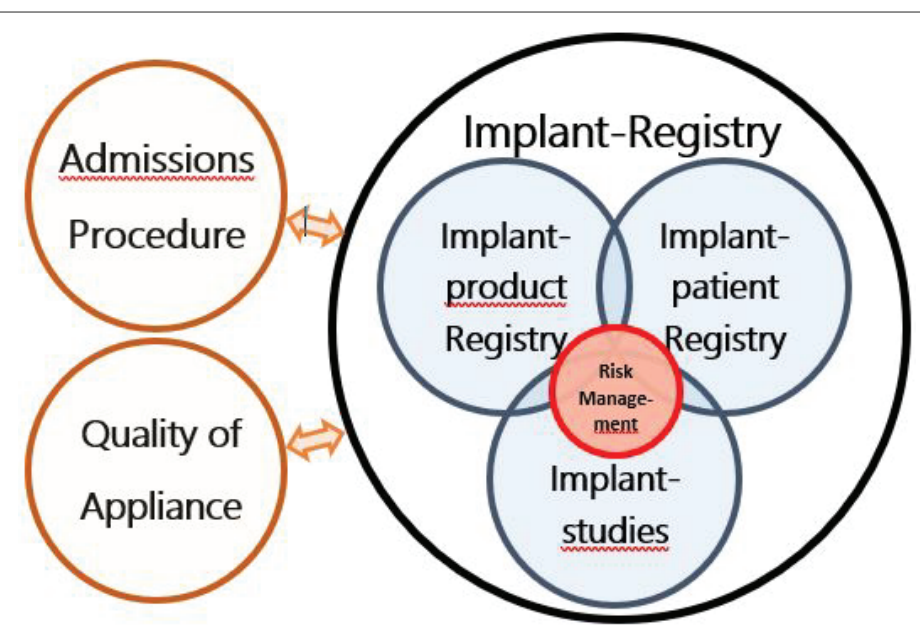

Figure 1: Three tasks to derive the greatest benefit from an implant register. Problem management plays a central role from the patient's point of view. Just as important are the approval procedure and the quality of application.

Table 1: Data for recording in an implant product register.

\begin{tabular}{|l|l|l|}
\hline \multicolumn{1}{|c|}{ Implant Key Data } & \multicolumn{1}{|c|}{ Additional Data } & \multicolumn{1}{c|}{ Additional Information (links) } \\
\hline Indications & Detailed material & General patient information \\
\hline Contraindications & Biocompatibility & $\begin{array}{l}\text { Special patient information (implantation, use phase, risks, } \\
\text { durability, what happens without the implant) }\end{array}$ \\
\hline Procedure & Material surface/contact areas & $\begin{array}{l}\text { Further information from scientific societies, manufacturers } \\
\text { and patient groups }\end{array}$ \\
\hline Desired effect (Objective) & $\begin{array}{l}\text { Manufacturing process (standard and custom } \\
\text { implants) }\end{array}$ & Training facilities \\
\hline Material & Technical features & Specific literature \\
\hline Photographic illustration(s) & Possible electronic properties & Definitions (Glossary) \\
\hline Imaging techniques (for identification \\
in the patient) & Expected time of function & \\
\hline Special features & Size and shape spectrum & \\
\hline Manufacturer & Additional components & \\
\hline Approvals & Sources of supply & \\
\hline Potential risks & Ability to perform implantation & \\
\hline Actuality & Standards & \\
\hline & Additional product qualities & \\
\hline
\end{tabular}

personalized examination. Due to the possibilities of digital planning in connection with additive and subtractive 3D technologies and the use of new materials, the number of individually patient-related implants will increase in the future. Special modes must be developed for this purpose.

Electronic medical devices: Electronic components in implants are becoming increasingly important. As a rule, biocompatibility is not the most important factor here, as they mostly are embedded in other materials, but the reliability of the function. Usually they can be regulated externally. This has already been tested (faulty programming [7], hacker risk [8]. Programming will increasingly enable individual solutions. Their quality control seems to be rather possible by algorithms supported by artificial intelligence.

Biological medical devices: Biological medical devices are usually no longer detectable in the long term. So the result only can be evaluated secondarily. There is a multitude of casuistiks available.
However, longitudinal studies are largely lacking. This is also due to the problem of the great individuality of both the initial findings and the surgical results. In addition, there is a great variety of products and different procedures that prevent usable comparative figures. The therapeutic effect is not always exactly predictable and assessable. Due to possible manifold interactions, drug-like reactions are also conceivable and could possibly be regarded as such by this group [6]. Implant drug combinations may also be included here. Implants obtained from patient cells are also individual, whereby the process of tissue extraction, tissue processing and traceability are in the spotlight.

Border areas: It cannot be entirely ruled out that implants which are not recorded may be inserted in agreement between the patient and the doctor. This is most likely conceivable in the area of simple materials (e.g. plaster), individualized implants (e.g. subperiosteal implants in the dental area) or illegal imports. 
Registration may also be problematic in the case of medical tourism associated with implants. It cannot always be assumed that patients register on their own initiative. In addition, the focus in these cases may be on cost reduction, which in turn can be associated with undercover payments and even insurance fraud $[9,10]$.

Innovations: In the past, implants were also introduced by individuals or small institutions. Some of these have given important impulses. With the increase in the density of regulations and liability problems, this is hardly possible today. In addition, implants are becoming more complex and individuals are no longer in a position to develop marketable products. As much as regulation is desirable, it can also hinder progress. In the case of large institutions, transparency usually prohibits irregular procedures. It would be useful to develop special regulations for individual inventors or small groups. This could, for example, be a specially controlled and tutored register to be defined, linked to an approval procedure.

\section{Implant patient registry}

The more advanced approach is to link patients with inserted implants to the implant product register. Let us call this "implant patient registry" or "implantation registry" [11]. Reason for this is the desire for traceable product quality and its control. Initially only linking the name of the patient and the medical device used by him is at first sufficient. Thus, if one day each inserted implant is registered patient related, it will be easy to determine its quality as far as it is reflected in the time of integration.

The question is whether the effort is justified to set up an implantpatient register that covers more than $99 \%$ of successful implants (examples: breast implants, cardiac pacemakers). The problems that have become known were mainly due to inadequate approval procedures, a primary task of state institutions. It is logical to meet this in the future with improved approval procedures, for which great efforts are now being made (e.g. CE, FDA) [12]. Primarily, this does not lead to the necessity of establishing an implant registry, as this would most probably not have allowed the problems to be detected earlier. However, there may be additional benefits.

The demand for more parameters that can measure the success of an implant goes even further ("Clinical Quality Registries, CQR") $[2,11]$. This goes far beyond linking an implant with a patient. It raises the question of data clarity and the cost/benefit ratio. From a scientific and patient point of view, this is what makes a register valuable.

Question: Couldn't one achieve at least the same and a more focused result if an efficient failure management and reporting system were introduced and the reasons for the failures were addressed?

Implant patient registries have so far been established in those areas where faults can induce severe or life-threatening consequences for patients. These are usually understood to mean the following implants: Heart valves, non-absorbable vascular implants, joint implants for hips and knees, spinal implants, breast implants. A rough scale may be a classification into risk groups for medical devices [13]. Whether further implant applications should also be covered by patient registers in the future should only be examined when sufficient experience has been gained $[4,14,15]$.

Excerpt: In 2018, a journalistic review of implant faults caused a sensation. Implant files (ICIJ) $[16,17]$ found that "health institutions globally failed to protect millions of patients from poorly tested implants". This attracted a great deal of attention. Some states felt motivated to initiate implant registries.
ICIJ quotes alarming figures: 80,000 deaths and 1.7 million injuries from implants, a fivefold increase in the number of events in the past ten years in the USA and a threefold increase in Germany. Both in the USA and in Europe (EU and 30 nations) a lack of publication activity of the institutions was complained about implant errors.

Surprisingly, these figures were presented by investigative journalists and not by institutions or scientists. This enabled the perception that a closed, self-protecting community of physicians, scientists, manufacturers, testing institutions, government institutions, politicians and lobbyists has emerged in the field of implants. For each of these groups, more or less large motivations could be filtered out.

As important as these-still ongoing-publications are, they have to be questioned in detail. Failures are not set in relation to successes. Thus one is dependent on speculations in most areas. Failures are communicated more intensively than the total number of implantations or successes. This initiative is very important, but its statements must be put in a scientific context.

\section{Data Recording}

Implants are usually assigned to a patient by means of a code and are then easy to track. This is standard. It may be assumed that more patients received an implant card than are centrally registered. A central recording is carried out in very different ways depending on the subject. The number of implanted medical devices is therefore difficult to determine. Even with a product like the cardiac pacemaker, there are neither current nor reliable figures. 8 million implants are assumed $[18,19]$. After all, they can still be controlled in the implanted state by the electronic function. This is different for smaller implants, e.g. dental implants or osteosynthesis plates. Marking by micro inscriptions is possible, but not continuously realized and it is questionable whether the inscription can be read in vivo. Since the same result can be achieved through consistent documentation, the question of cost/benefit must be asked. In the case of biodegradable materials, the possibility of marking and traceability by the implant product is not applicable.

The implant cards used today to inform a patient and possible further therapists about an implant are only of limited use for statistical or scientific purposes-if only because they are not used consistently. However, they can help patients in case of problems in a simple way, e.g. during interventions, relocation or if the practice/clinic is no longer operated. With a digital patient "card", which unmistakably records the data of an implant, the tracking of an implant is centrally possible. This is helpful for the patient in case of loss of his documents, and it allows recall actions. The prerequisite is a functioning telematics infrastructure.

A distinction can be made between "document identifiable" implants and "product identifiable" implants, which can be precisely identified independently of the patient. With clear regulations for the bringing into circulation of medical devices, the more time-consuming product identification could be avoided. The latter, however, provides better protection against misunderstandings or fraud-where relevant.

With regard to identifiability, three groups of implantable medical devices can be distinguished: Definitely identifiable implants, difficultto-identify implants and unidentifiable implants (Table 2). Since the later identification of the last two groups is difficult or impossible today, the recording of the implantation during the procedure ("document identification") is the decisive link that allows an implant to be clearly assigned to a patient. The precise recording is common today for most life-supporting or problematic implants, but only there. There are also 
Table 2: Product identification of implants after implantation.

\begin{tabular}{|c|c|c|c|}
\hline & Identifiable Implants & Hardly Identifiable Implants & Non-Identifiable Implants \\
\hline & Vital function & Smallness & Biodegradable implants \\
\hline & Manageable number & High number of units not verifiable & Implants changing in the biological environment \\
\hline & & Difficult to mark & Custom implants D \\
\hline & Size & Not reliably identifiable after implantation & \\
\hline & $\begin{array}{l}\text { Identifiable after implantation } \\
\text { (implant-bound) }\end{array}$ & & \\
\hline & Non-degradable & & \\
\hline \multirow[t]{3}{*}{ Examples } & Pacemaker & Osteosynthesis plates and screws & Resorbable bone graft substitutes \\
\hline & Joint endoprostheses (hip, knee) & Dental implants & Membranes, soft tissue implants \\
\hline & & Soft implants & Vascular prostheses \\
\hline
\end{tabular}

regional differences. The full coverage realization and establishment of the compatibility of different systems is expected to require a great deal of effort, especially from an international point of view. Accompanying problems of a consequent implant registration beginning with the production over the sale all the way to the implantation are the traceability of the storage and the finding of unused or outdated implant types.

A more or less complete coverage would compensate or replace the current lack of long-term studies. Thus, the previously required prospective longitudinal study-hardly feasible in this area anyway-has become obsolete and can give way to a factual study.

The question of how to record and evaluate implants whose wearers will carry them to the end of their lives appears to be hardly manageable. As expected, this affects the vast majority of implants. It is doubtful whether the effort required for this is at all effective, i.e. serves patient safety. There would have to be a link with the death registers. Even taking data protection into account, such evaluations should at best be reserved for special scientific investigations.

An interesting question is whether by collecting discrete findings; data sets can be obtained from which warnings can be filtered using algorithms that will make it possible in future to detect undesirable developments at an earlier point in time. This requires access to a central system equipped with artificial intelligence for each examining and maybe lay person.

From a scientific point of view, it can be helpful to record the post mortem status of an implant, as this provides the opportunity to examine the functionality and integration of an implant in detail. The establishment of the German Histological Implant Register sets an example here [20]. This measure can only cover a small part of the implants and therefore is only relevant for special scientific questions. The desire to collect explanted implants centrally and examine them for traces of use points in a similar direction [21].

\section{Data Protection}

The collection of the implants is not a problem for data protection reasons, as long as no personal data are collected. At best the disclosure of product characteristics can lead to problems of competition protection.

More important is data protection in connection with personal data, i.e. the patient on whom the implant was implanted. If only the name in connection with the implanted product is known, this may also be easy to do with the patient's consent. It may happen that a patient refuses to disclose the link between an implant and his or her person. Irrelevant for what reason this happens. Where patient-related data is documented, clear dividing rules should be defined that do not affect personality rights. It is conceivable that made anonymous data can be used for specially defined scientific questions. A patient's right of refusal should be unaffected. This may be achieved through political regulations.

The proposed recording from sales by manufacturers also makes little sense, since not all implants sold are used. Also the way to pursue the data of insurances (invoice receipts) does not achieve the purpose consequently. Even if this could be improved, for example, by legislative measures, the disclosure of this data by insurance companies is questionable for data protection reasons. It is a political decision to what extent all these data should be networked and thus become more transparent for laymen.

The opt-out solution found in the Netherlands is interesting (breast implant register [22]. Initially, all patients are recorded, but they can decide for themselves whether they want to be removed from the register again.

The prospect that, in a totalitarian system, the entire population can be recorded and monitored in all its personal belongings can no longer be ruled out today. In such a future, implants would only be a small part of a surveillance structure. This is a problem of how we want to arrange our society.

\section{What is a Success with Implants?}

The success or failure of an implant is usually not only caused by the implant. A multitude of other factors can have an impact. The influences can vary depending on the implant type.

An example can be knee endoprosthesis treatment. The Institute for Quality Assurance and Transparency in Health Care (IQTIG) in Germany has published a detailed "Description of Quality Indicators for the Year 2016". In one of the partial studies, 24 data fields are evaluated and a total of 167 studies are listed. Only the expert is in a position to deduce from this that knee TEPs have a survival rate of $97 \%, 89 \%$ and $78 \%$ after 5,10 and 15 years [23].

If the scientific approach to defining success is difficult, it becomes even more complicated if the patient is interviewed. According to a systematic literature review with data from 2005 to 2016 , the satisfaction of patients with knee TEP depends primarily on the expectations before the procedure, the extent of functional improvement and the course of pain. $20 \%$ of patients expressed dissatisfaction [24,25]. 
Many physicians may also be aware of the situation where an implant should be removed or replaced according to medical criteria and in order to prevent consequential damage, but the patient says that he is satisfied with his situation.

Small databases (e.g. only success/failure) do not satisfy the scientific interest. Many parameters have to be accepted, i.e. cannot be influenced by the doctor. Possible influences are very different for different implant types. A mechanical impact or the functionality of an electronic component is relatively easy to assess if it is a standard procedure for placing an implant and if the variables of the procedure are manageable. Less comprehensible at the time of implant damage are the preconditions, beginning with the decision on implantation up to the healing process. Only good documentation can help. In the case of biodegradable or integrable implants, an examinable medium usually is no longer available at the time of damage. At best, the damage can be inspected which rarely shows whether it was caused by, without or despite the implant. Table 3 shows an overview of the most important parameters.

If all these factors could be recorded, it would be possible to judge more precisely the success or failure of an implant. It is difficult to determine the failure of an implant without knowing the circumstances. If this were to be introduced in general-understandably from a scientific point of view-it would have a far greater consequence in terms of data protection law. The most very own personal data would be disclosed. Some may refuse to do so. In the future, the use of block-chain technology and artificial intelligence could be an option to completely individualize and protect data.

The question of how to deal with secondary influences on implant success is difficult to answer. As far as this is possible for data protection reasons, at least the data from the patient file or electronic card can be accessed in addition to the implant incorporation duration. From that information, the age and sex of the patient and any illnesses can be recorded and evaluated with regard to their influence on the success of the implant. Equally important would be diseases or medications that occur later. Accordingly, an association of medical technology [26] also demands the recording of operating sites, surgeons and patient behavior.

A premature loss of an implant is a crucial event in the acquisition of data that must be recorded, documented and passed on promptly. The best way to determine which secondary parameters may have caused the failure is to record it promptly. At this point, the question can usually be answered as to whether it was a defect in the implant or other influences that may have been added later that led to the failure. The prerequisite is, of course, a systematic recording of the causes. If patient information reaches the author today, such as "lost the implant" or "patient died of the implant", no conclusions can be drawn without further re-examination.

\section{Existing Registers}

A large number of registers have been established. Currently 75 have been found. The vast majority are implant patient registers (Figure 2). Some registers are not continued. 7 new registers are currently being planned or in the data acquisition phase.

As a rule, the registers deal with implants for a specific indication. Endoprosthetic registers [12] and registers for cardiovascular implants [6] are in the first place. Registers for contour implants (esthetic indications) are represented by 12 and registers for all implants by 7 . 12 registers deal with further sub-areas of implant medicine (Figure 3 ).

\section{product registry patient registry \\ active \\ inactive \\ planned}

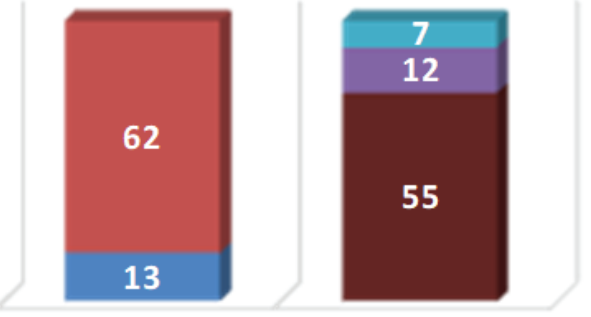

type of registry activity

Figure 2: Types of registers.

\section{" endoprosthesis匹 cardiovascular \\ घ esthetic $\quad$ general \\ unspecified}



Figure 3: Themes of registries.

The Registry of Registries (RoR) has not yet been established. The EU has launched the PARENT Initiative (Patient Registries Initiative) [27]. This initiative also intends to carry out a Health Technology Assessment (HTA). This means a process based on scientific evidence for the systematic evaluation of health technologies, procedures and aids, but also organizational structures in which medical services are provided. At present, the third stage of EUnetHTA from 2016-2020 is running. It remains to be seen whether the very ambitious goals, which go far beyond implants, will be achieved [28].

The European Federation of National Associations of Orthopedics and Traumatology (EFORT) developed the European Arthroplasty Register EAR for endoprosthetics for 41 countries, which can serve as a blueprint for international cooperation (https://www.efort.org).

In the field of aesthetic surgery, a disease-related register was introduced to assess the consequences of certain implants (ALCLRegistry, McCarty CM, et al. [3,29]. 
Table 3: Influences on implant success.

\begin{tabular}{|c|c|c|c|c|}
\hline Implant & Patient Data & Indication, Planning & Performance & Time of Function \\
\hline Manufacturer & Patient & Doctor & Doctor & $\begin{array}{l}\text { Patient/Doctor/ } \\
\text { Implant }\end{array}$ \\
\hline $\begin{array}{l}\text { Product material } \\
\text { Product quality } \\
\text { Biocompatibility } \\
\text { Administration }\end{array}$ & $\begin{array}{l}\text { Degree of damage } \\
\text { State of health } \\
\text { Medications } \\
\text { Understanding the } \\
\text { treatment } \\
\text { Anatomical conditions }\end{array}$ & $\begin{array}{l}\text { Scope of diagnostics } \\
\text { Planning (aids) } \\
\text { Alternatives } \\
\text { Risk behavior } \\
\text { Intervention Logistics } \\
2^{\text {nd }} \text { opinion } \\
\text { Artificial Intelligence }\end{array}$ & $\begin{array}{l}\text { Method Experience Skill } \\
\text { Form on the day } \\
\text { Robotics } \\
\text { Equipment } \\
\text { Working conditions } \\
\text { State of continuing } \\
\text { Education } \\
\text { Risk behavior } \\
\text { Staff } \\
\text { Operational course }\end{array}$ & $\begin{array}{l}\text { Healing process Life style } \\
\text { Change in health status } \\
\text { Change in living conditions } \\
\text { Medications } \\
\text { Checks } \\
\text { Functional behavior } \\
\text { Singular Events } \\
\text { Secondary interventions }\end{array}$ \\
\hline
\end{tabular}

state

industry

unspecified

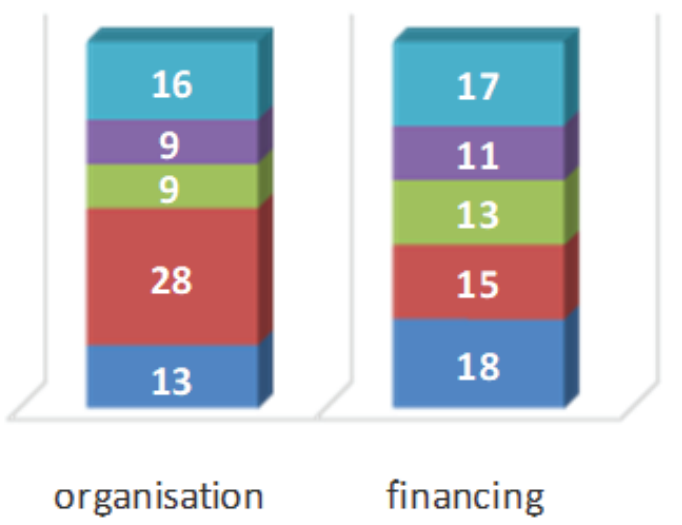

Figure 4: who's running registries.

The initiators of existing registers are usually the relevant scientific associations $[2,9,14,20,30-31]$ which predominate in the organization of registers (Figure 4), followed by state institutions.

The professional associations like to use health insurance companies and medical technology associations (e.g. endoprostheses registers) for financing. The most common form of financing is provided by states. Insurance companies have a vested interest in evaluating costintensive developments. An outstanding example of this is registration in the USA at 50 hospitals with 2,400 participating doctors, 445,000 patients and 550,000 treatments over a lifetime. 2.15 million Implants were registered and 133 publications were produced (https://nationalimplantregistries.kaiserpermanente.org).

The question how to achieve complete independence is unanswered and should be sought as a superior quality. Conflicts of interest may arise between all parties. This is obvious in the manufacturing industry, but undesirable influences can also arise in the case of government bodies that like to make use of university staff. Conflicts of interest are possible in many ways. Universities are partly associated with manufacturers, university representatives run their own implant companies or conduct research for them, and are represented in committees. The publication of public registers and guidelines, in turn, influence market developments. The active and financially extensive lobbying in the medical sector is well known [32,33]. This can promote, hinder and guide development. Transparency International considers healthcare to be particularly vulnerable to corruption [34]. This suggests that responsibilities should be distributed.

A comprehensive and unique global implant product register is the Implant-Register/implantwiki ${ }^{\circledR \star}$, which currently comprises approximately 4600 implants and 650 implant manufacturers from all areas of human implants. It is completely independent. In addition to the list of implants and manufacturers, you will also find patient information and all scientific associations dealing with the subject of implants. As an international registry, it cannot collect patient data, but it can collect national studies and make them available to an international audience.

Today, implant registers are largely organized on a national basis. However, the institutions are partly in exchange and one can hope that in the course of time real cooperation will develop. The implants are usually distributed multinationally, so that the creation of international knowledge and its networking certainly is helpful. The compatibility of digital platforms should be considered at an early stage [35].

\section{What are the Benefits of Implant Registers?}

First of all, the demand for an implant register sounds reasonable and one is willing to agree to it without hesitation. Nevertheless, the question should be posed as to what benefits actually arise and what meaningful information can be gained. The benefit for the patients concerned must be the top priority. However, the patient also benefits from the knowledge gained by doctors, scientists, manufacturers and self-help groups.

» The first objective must be to prevent the use of unsuitable implants (approval procedure).

» In the second place should be that those affected by damage can be helped as quickly as possible. The ideal case would be that all affected patients could be informed directly by a register and at the same time a solution to the problem would be proposed. In 
addition to the previous recording of the patient's and implant's unity, this requires an up-to-date communication management.

» The third objective of an implant register can be to learn from mistakes and failures in order to avoid or at least reduce them in the future. The intention can also be to provide impetus for improving the product quality of implants. With increasing life expectancy and the immense increase in implantations, many late effects of implants will probably only become known in the future.

The last but not least information should be shown to all interested parties. In the past, medical registers were usually only addressed to professionals. That's not the case today. Not only the work of journalists, but also the public of the modern information society will have an influence on the hitherto rather closed knowledge community in implantology.

According to the Federal Ministry of Health in Germany, more than half of the problems with implants are product-related-and only half of the implants were examined [36-37].

\section{Discussion}

What is the most effective approach to patient safety and what role can an implant register play on this? Solid, independent, scientific work is required to obtain knowledge that benefits patients. This means first of all finding the right question, which is certainly not only subject to factual but also contemporary changes. On this basis, the data available through an implant register can then be evaluated. As a rule, further investigations are required in order to obtain reliable results. Due to the large variance of the parameters and the individuality of medical treatments, pure material testing, as it is known from consumer tests, is not effective.

Statistical findings can be used to change the behavior of doctors. If, for example, an endoprostheses register shows that acutely inserted hip endoprostheses require a second operation twice as often, this will save many patients a second operation by changing their doctor's behavior $[38,41]$.

As many parameters as possible that influence the success of an implant must be examined in the studies (Table 3). The desire for great precision is challenged by the problems of data acquisition and confusion. At this point, however, it must be understood that the feasibility and disputability of a register are related not only to the quantity but also to the quality of the data volumes. It is difficult to find the right measure, but it is advisable to start with manageable data sets when setting up a register and only expands the parameters when they are functioning.

This can also result in regularity for the submission of investigations, which, however, must always be questioned anew. A multitude of subsequent and new developments must be expected. Such a system must be able not to hinder development. Rigid specifications and networks are not suitable, especially when it comes to disruptive developments. The scientific societies are asked to continuously give the appropriate impetus.

For many of the reasons mentioned above, it may be appropriate to divide implant registers into three parts. These must be both interlocking and independent to avoid mutual influence. For the patient, the focus is on problem and risk management, which can access this data (Figure 1).

In all implant evaluations, the existing shortcoming will continue to exist: Almost all implants remain for such a long time that the previously used implant has long since been replaced by successor models.

At this point, the importance of the approval of implants and the quality of their application (user training, working environment) should be recalled (see above), which may be of greater importance for the prevention of implant problems. According to the Federal Ministry of Health in Germany, more than half of the problems with implants are product-related-and only half of the implants were examined [38].

Hopefully digitization and the associated standardization will make data collection simpler and therefore more reliable. A secure and largely automatic process can also be more easily delegated and integrated into administrative processes. It may be wiser to wait until the digital infrastructure is up and running.

The danger exists to create a data and financial monster that, due to its complexity, brings little benefit. Networking the problems from the medical to the political and journalistic environment could lead to a change in the objective. In the large field of data volumes, the direct patient-doctor relationship remains a valuable asset worth protecting.

\section{Conclusion}

The decisive parameters for the success of implants are reliable approval procedures for the products, good education and training of the physicians and a quality-oriented working environment. This can be supported by a definition of quality indicators $[17,42]$. The implant register is a partial benefit (Figure 1).

\section{Conflict of Interest}

*Implant-Register/implantwiki® (conflict of interest, nonprofit site).

\section{References}

1. National Implant Registry Established by ECRI (1982) Orthopedics 5: 491.

2. Brown T, Merten S, Mosahebi A, Caddy CM (2016) Breast Implant Registries: The Problem with ambition. Aesthetic Surg J 36: 255-259.

3. McCarthy CM, Loyo-Berríos N, Qureshi AA, Mullen E, Gordillo G, et al. (2019) Patient Registry and Outcomes for breast Implants and anaplastic large cell Lymphoma Etiology and Epidemiology (PROFILE): Initial Report of Findings, 2012-2018. Plast Reconstr Surg 143: 65S-73S.

4. Roberts M: Women missing from breast implant register, BBC News, 14 March 2018.

5. Ehrl PA: Implant-Register.

6. Agency for Healthcare Research and Quality/AHRQ (2014) Registries for Evaluating Patient Outcomes: A User's Guide. In: Gliklich RE, Dreyer NA, Leavy MB (eds), $3^{\text {rd }}$ Edition, U.S. Department of Health and Human Services, USA.

7. Medtronic (2019): Urgent Medical Recall for a subset of Medtronic dual chamberpacemaker.

8. The Guardian: Hacking riskleads to recall of 500.000 pacemakers due to patientdeathfears, August 2017.

9. Fitzgibbon W (2019) Implant tourism leaves patients in pain and far from their surgeon, Medical tourism operators are luring patients to Africa for operations that leave them in crippling pain and with little more than WhatsApp messages for support.

10. Lenzlinger $R$, So schamlos werben Schweizer Kliniken für Schönheits-OPs, Schönheits-OP als Unfall deklariert, 13 Oct 2018, Blick (Switzerland). 
11. Serra-Sutton V, Allepuz A, Espallargues M, Labek G, Pons JM (2009) Arthroplasty registers: a review of international experiences. Int Technol Assess Health Care 25: 63-72.

12. Mulero A (2018) VA Moves to Launch Implant Registry with FDA, CMS, DoD Input, Regulatory Focus.

13. European Parliament and Council: Regulation (EU) 2017/745 on medical devices 05.04.2017, Official Journal of the European Union, 05.05.2017, L 117/1.

14. Berrettini S, Arslan E, Baggiani A, Burdo S, Cassandro E, et al. (2011) A registry for the collection of data in cochlear implant patients. Acta otorhinolaryngol Ital 31: 328-340.

15. Gesetz zur Errichtung eines Deutschen Implantateregisters (Implantateregister-Errichtungsgesetz-EDIR), Beratungsstand 28.01.2019.

16. Implant Files

17. Jaschensky W, Langhans $\mathrm{K}$, Obermaier F, Obermayer B, Wiegand R (2018) Das sind die Implant Files, Süddeutsche Zeitung.

18. How Many People Have Pacemakers, World Society of Arrhythmias.

19. Wood MA, Ellenbogen KA (2002) Cardiology patient pages. Cardiac pacemakers from the patient's perspective. Circulation 105: 21362138.

20. DGOOC (2018) Gründung des "Histopathologisches Implantatregister".

21. Ärzteschaft (2018) Fachgesellschaften regen strukturierten Umgang mit ausgedienten Implantaten an, Deutsches Ärzteblatt.

22. Rakhorst HA, Mureau MAM, Cooter RD, McNeil J, van Hooff M, et al. (2017) The new opt-out Dutch National Breast Implant RegistryLessons learnt from the road to implementation. J Plast Reconstr Aesthet Surg 70: 1354-1360.

23. IQTIG (2016) Knieendoprothesenversorgung. Ergänzung zur Beschreibung der Qualitätsindikatoren für das Erfassungsjahr 2016.

24. Gunaratne R, Pratt DN, Banda J, Fick DP, Khan RJK, et al. (2017) Patient Dissatisfaction Following Total Knee Arthroplasty: A Systematic Review of the Literature. J Arthroplasty 32: 3854-3860.

25. Fath R (2018) Ein anspruchsvoller Gelenkersatz, Die Zufriedenheit von Patienten mit Knie-TEP hängt in erster Linie von den Erwartungen vor dem Eingriff, vom Ausmaß der Funktionsverbesserung und dem Schmerzverlauf ab. Knie-Totalendoprothesen 115: A-332 / B-284 / C-28.

26. Schmitt JM: BVMed-Stellungnahme zum Referentenentwurf eines Gesetzes zur Errichtung des Deutschen Implantateregisters und zu weiteren Änderungen des Fünften Buches Sozialgesetzbuch (Implantateregister-Errichtungsgesetz-EIRD), BT-Drs. 19/10523, Deutscher Bundestag, Ausschuss für Gesundheit.
27. Karanikas $\mathrm{H}$, Meglic M, Doupi P, PARENT-Joint Action cross-border PAtientREgistriesiNiTiative, Patient Registries \& HTA, 2014.

28. Eunethta (2016-2020) EUnetHTA Joint Action 3.

29. Hopper I, Ahern S, Nguyen TQ, Mulvany C, McNeil JJ, et al. (2018) Breast Implant Registries: A Call to Action. Aesthetic Surg J 38: 807810.

30. Ebeling PR, Akesson K, Bauer DC, Buchbinder R, Eastel R, et al. (2019) The efficacy and safety of vertebral augmentation: A second ASBMR task force report. J Bone Miner Res 34: 3-21.

31. Niederländer C, Wahlster P, Kriza C, Kolominsky-Rabas PL (2013) Registries of implantable medical devices in Europe. Health Policy 113: 20-37.

32. Bowers S (2018) How Lobbying Blocked European Safety Checks For Dangerous Medical Implants, ICIJ.

33. Stein C (2001) Kritik an der Leitlinien-Erstellung, Transparency International, Deutschland e. V.

34. Stein $R$, Die Übermacht der Lobby im Gesundheitswesen (thesupremacy of lobby in publichealth), Berliner Ärzte 2001, 12, 26-28.

35. Sadoghi P, Leithner A, Labek G (2013) Overcoming Boundaries of Worldwide Joint Arthroplasty Registers: The European Arthroplasty Register Minimal Dataset. J Arthroplasty 28: 1327-1328.

36. Der Spiegel (2018) Gefährlicher Informationsmangel bei Implantaten.

37. Cooter RD, Barker S, Carroll SM, Evans GR, von Fritschen U, et al. (2015) International importance of robust breast device registries. Plast Reconstr Surg 135: 330-336.

38. Grimberg A (2016) Endoprosthesis Register (Germany) shows reasons for early replacements, Deutsche Gesellschaft für Orthopädie und Orthopädische Chirurgie.

39. Medizinprodukte (2012) Europaweites Register soll Sicherheit bringen. Der Spiegel.

40. Poly Implant Prothese.

41. Wurzer P, Rappl T, Friedl H, Kamolz LP, Spendel S, et al. (2014) The Austrian breast implant register: recent trends in implant-based breast surgery. Aesthetic Plast Surg 38: 1109-1115.

42. VERORDNUNG (EU) 2017/745 Des Europäischen Parlaments Und Des Rates (2009) Amtsblatt der Europäischen Union. 